\title{
Polymer Based Nano-Formulation of Diindolylmethane with High Oral Bioavailability
}

Vsevolod Kiselev ${ }^{1}$ Eugenii Klinskiy², Shengmin Lee ${ }^{2}$, Ekaterina Muyzhnek ${ }^{3}$, Alexander Semov² and Valery Alakhov²*

${ }^{1}$ National Research Centre "Kurchatov Institute", Moscow, Russia

${ }^{2}$ Supratek Pharma Inc. Montreal, Quebec, Canada

${ }^{3}$ MiraxBioPharma, Moscow, Russia

\begin{abstract}
At the present, a high potential of 3,3'-diindolylmethane (DIM) as a new preventive and therapeutic agent in oncology is well established, due to its ability to target multiple components of cancer cell cycle regulation, survival and progression. However, a very low bioavailability of DIM remains the major challenge for its efficient development as novel medicine. In this work, we have developed a polymer based nano-formulation comprising a non-ionic block copolymer, Pluronic F127 that increases oral bioavailability of DIM by almost one order of magnitude, as compared to the presently marketed products such as crystalline DIM and BioResponse DIM. The pharmacokinetic parameters established in the present study revealed that $A \cup C$ and $C_{\text {max }}$ of the new formulation dosed at $60 \mathrm{mg} / \mathrm{kg}$ were $7.06 \pm 0.93$ $\mu \mathrm{g} \cdot \mathrm{h} / \mathrm{mL}$, and $3.08 \pm 0.17 \mu \mathrm{g} / \mathrm{mL}$, while in the case of crystalline DIM dosed at the same dose AUC and C were 0.97 $\pm 0.08 \mu \mathrm{g} \cdot \mathrm{h} / \mathrm{mL}$, and $0.18 \pm 0.02 \mu \mathrm{g} / \mathrm{mL}$. BioResponce DIM showed AUC and $\mathrm{C}_{\max }$ of $1.05 \pm 0.05 \mu \mathrm{g} \cdot \mathrm{h} / \mathrm{mL}$, and 0.22 $\pm 0.02 \mu \mathrm{g} / \mathrm{mL}$, respectively.
\end{abstract}

Keywords: Diindolylmethane; Pluronic F127; Bioavailability

\section{Introduction}

Epidemiology studies demonstrate that dietary consumption of cruciferous vegetables, including broccoli, cauliflower and Brussel's sprouts may provide protection from some chronic diseases, including several types of cancer [1]. Phytochemicals derived from cruciferous vegetables include indole-3-carbinol (I3C) and its condensation product, 3,3'-diindolylmethane (DIM). Because I3C in cell culture medium or in stomach is readily converted into DIM, most of the responses observed for $\mathrm{I} 3 \mathrm{C}$ in vitro and in vivo have been related to DIM activity [1,2]. Anti-cancer properties of DIM are well-known $[2,3]$. It targets multiple components of cancer cell cycle regulation and survival, including Akt/NF- $\mathrm{kB}$ signalling, caspase activation, cyclin-dependent kinase activities, estrogen receptor signalling, and endoplasmic reticulum stress. DIM also inhibits invasion of cancer cells and tumor neoangiogenesis. It has been shown that DIM interacts and activates aryl hydrocarbon receptor (AhR) [4]. The AhR is a transcription factor, known primarily as a receptor for toxins such as 2,3,7,8-tetrachlorodibenzo-p-dioxin and some non-toxic ligands. AhR activation plays an important role in the chemopreventive effects of DIM. Specifically, it up-regulates gene expression of the detoxification Phase I enzyme CYP1A1 and the Phase II enzymes glutathioneS-transferase and oxireductases [2]. These enzymes accelerate the metabolism of genotoxic agents, either environmental or endogenous, thus preventing the development of carcinogen-induced tumors.

We have recently reported that DIM is a selective and potent inhibitor of cancer stem cells (CSCs) [5]. In a panel of cancer cell lines, DIM inhibited tumor sphere formation at the concentrations up to 300 times lower than concentrations required for growth inhibition of parental cells cultured as adherent culture. We also found that treatment with DIM overcomes chemoresistance of CSCs to conventional cytotoxics, such as paclitaxel, doxorubicin, and SN-38. Pre-treatment of tumor spheres with DIM before implantation to mice significantly retarded the growth of primary tumors, in comparison with tumors formed by non-treated tumor spheres.

The unique selectivity of DIM, with respect to CSCs and drug resistance, when combined together with its other well-known biological activities, offers a novel and powerful tool for cancer therapy and prevention. However, therapeutic utility of this compound is limited by its very low solubility and bioavailability [6], and new formulations with improved bioavailability are highly required to reach therapeutically meaningful levels of DIM in circulation. One of such formulation has been recently established and known as BR-DIM (BioResponse DIM) (BioResponse, LLC, Boulder, Co), oral formulation of DIM that exhibits $50 \%$ higher bioavailability compared to the crystalline compound. At the present, BD-DIM is in multiple clinical studies [6]. The concentrations of DIM required to suppress CSCs formation are in the close range to those achievable in human plasma, after oral dosing of the BR-DIM composition. However, a more efficient formulation with additionally increased oral bioavailability of the compound could help fully explore potential of DIM as pharmaceutical agent.

In this work, we have described a new composition of DIM that demonstrates a much greater oral bioavailability, as compared to both crystalline DIM and BR-DIM, and allow achieving close to 10-fold increase in systemic exposure of the compound [7]. The new formulation is based on non-ionic block copolymer, Pluronic F127 that is known as highly safe excipient, and is used in multiple pharmaceutical, nutritional and cosmetic products.

\section{Materials and Methods}

\section{Reagents}

DIM was purchased from Alexis Corporation, BR-DIM was

*Corresponding author: Valery Alakhov, Supratek Pharma Inc., Montreal, Quebec, Canada, Tel: 1-514-422-9191; Fax: 1-514-422-9410; E-mail: valery.alakhov@supratek.com

Received December 10, 2012; Accepted February 06, 2013; Published February 08,2013

Citation: Kiselev V, Klinskiy E, Lee S, Muyzhnek E, Semov A, et al. (2013) Polymer Based Nano-Formulation of Diindolylmethane with High Oral Bioavailability. J Nanomed Nanotechol 4: 162. doi:10.4172/2157-7439.1000162

Copyright: $\odot 2013$ Kiselev V, et al. This is an open-access article distributed unde the terms of the Creative Commons Attribution License, which permits unrestricted use, distribution, and reproduction in any medium, provided the original author and source are credited. 
Citation: Kiselev V, Klinskiy E, Lee S, Muyzhnek E, Semov A, et al. (2013) Polymer Based Nano-Formulation of Diindolylmethane with High Oral Bioavailability. J Nanomed Nanotechol 4: 162. doi:10.4172/2157-7439.1000162

Page 2 of 3

purchased from BioResponse Inc.; Pluronic F127 was a kind gift from BASF Corporation.

\section{Animals}

Female Sprague-Dawley rats $(250-350 \mathrm{~g})$ were purchased from Charles River Canada Inc. (St. Constant, Quebec, Canada). The animals were kept three per cage with an air filter cover under light (12 h light/ dark cycle, light on at $06 \mathrm{~h} 00)$ and temperature $\left(22^{\circ} \mathrm{C} \pm 1^{\circ} \mathrm{C}\right)$ controlled environment. All manipulations with the animals were performed under a sterilized laminar hood. The animals had ad libitum access to Purina mouse chow (Pro Lab PMH 4018, Trademark of Agway, Syracuse, New York) and water. The animal studies were conducted according to the "Guidelines for Care and Use of Experimental Animals". The animals were fasted overnight and anesthetized, before perfusion starts.

\section{Formulation preparation}

The F127-DIM formulation was prepared by co-dissolving DIM and Pluronic F127 in ethanol, followed by evaporation of the solvent till dryness, and, finally by reconstituting the dry matrix in distilled water to the final concentrations of DIM and Pluronic F127 of $3 \mathrm{mg} / \mathrm{ml}$ and $20 \mathrm{mg} / \mathrm{ml}$, respectively.

The control dosing solution of DIM was prepared by suspending 15 $\mathrm{mg}$ of DIM in $5 \mathrm{~mL}$ of $0.5 \%$ methyl cellulose in distilled water.

The BR-DIM (BioResponse DIM 75 ) dosing solution was prepared by suspending the content of two Bioresponse DIM 75 capsules $(150$ $\mathrm{mg}$ ) in $50 \mathrm{~mL}$ of distilled water. Therefore, all the dosing solutions contained $3 \mathrm{mg} / \mathrm{mL}$ DIM; they were administered immediately after the preparation.

\section{Animal dosing and sampling}

DIM formulations and control (non-formulated compound) were orally administered to groups of 6-8 week-old female rats (4 animals per group) by gavage at the dose of $60 \mathrm{mg} / \mathrm{kg}$. After various time intervals $(15,30,45 \mathrm{~min}, 1,2,4$, and $6 \mathrm{~h})$ post-dosing, the blood samples were collected. The rats were anesthetised by general inhalation of Isoflurane (Bimeta-MTC, Animal Health Inc. Cambridge, ON, Canada). The blood samples were collected from the jugular vein with the heparinised tube, and kept immediately on ice for 5 to $10 \mathrm{~min}$. Blood was immediately centrifuged and plasma was separated. The plasma samples were immediately frozen in dry ice and stored at $-80^{\circ} \mathrm{C}$, until further use.

\section{Sample extraction and analysis}

The plasma samples were defrosted, centrifuged, and aliquots (100 $\mu \mathrm{L}$ ) were transfered to plastic tubes and extracted twice with $750 \mu \mathrm{L}$ of tret-butyl methyl for $2 \mathrm{~min}$, each time by shaking on $180^{\circ} \mathrm{C}$ rotator. The samples were centrifuged at $10,000 \mathrm{rpm}$ for 10 minutes. The supernatants were separated and transferred to glass tubes. The organic phase was evaporated in the stream of nitrogen at $50^{\circ} \mathrm{C}$, until dryness. The dried samples were kept at $-80^{\circ} \mathrm{C}$ before the HPLC analysis. The samples were dissolved firstly in $15 \mu \mathrm{L}$ of acetonitrile, and then diluted with $85 \mu \mathrm{L}$ of mobile phase. The aliquots of $20 \mu \mathrm{L}$ were injected into HPLC for analysis.

The HPLC conditions were as following: $\mathrm{C}_{18}$ reversed phase column $50 \times 4.6 \mathrm{~mm}$, Symmetry/Shield $3.5 \mu \mathrm{m}$, column temperature $30^{\circ} \mathrm{C}$, flow rate $1.5 \mathrm{~mL} / \mathrm{min}$, injection volume $20 \mu \mathrm{L}$, UV-detection at $\lambda=280 \mathrm{~nm}$, mobile phase: linear gradient of buffer B from $0-100 \%$, buffer A: $5 \%$ acetonitrile $0.1 \%$ TFA, buffer B: $90 \%$ acetonitrile $0.1 \%$ TFA, run time $10 \mathrm{~min}$.
The DIM concentrations were calculated from the area under the peak (AUP), by using calibration curve. The areas under the curves (AUC) were calculated by trapezoidal method.

\section{Results and Discussion}

Since aqueous solubility of DIM is very low, the formulation comprising DIM and Pluronic F127 was prepared by co-dissolving both compounds in ethanol, to allow for formation of molecular dispersion of the components. When the organic solvent was removed by evaporation, the resulted solid mass containing DIM and Pluronic F127 at the ratio of approximately 1:6.7, became soluble in water and formed transparent physically and chemically stable solutions, with DIM concentration of up to at least $3 \mathrm{mg} / \mathrm{ml}$. These solutions were used for the animal dosing by oral gavage for pharmacokinetics studies.

Figure 1 shows the results of plasma pharmacokinetics comparative study of non-formulated DIM, BR-DIM and novel Pluronic F127based DIM composition. Table 1 summarizes the calculated values of $\mathrm{C}_{\max }$ and AUC. The results illustrate considerably improved oral bioavalubility of F127-DIM formulation, compared to that of the conventional crystalline form of DIM and BR-DIM. As seen from the presented results, BR-DIM provides only marginal improvement of DIM pharmacokinetics (about 1.08-fold increase in AUC and 1.22fold in $\mathrm{C}_{\text {max }}$ ), while in the case of F127-DIM, a dramatic increase in bioavailability was observed (7.28-fold and 17.11-fold increase in AUC and $\mathrm{C}_{\max }$, respectively).

Based on the above results, the pharmacological properties of the new F127-DIM formulation should allow a dramatic improvement of this natural compound and possibly open new ways of its use, as both nutritional agent and pharmaceutical product. Importantly, Pluronic F127 is a well-proven, generally safe excipient that is broadly used as inactive ingredient in multiple marketed products [8], which provide a strong assurance of safe margin of F127-DIM formulation, and its quick and efficient introduction into human studies. At the present, based on the above described results, a new product Cineton ${ }^{\circledR}$ is being developed for commercial application in multiple areas. Preliminary

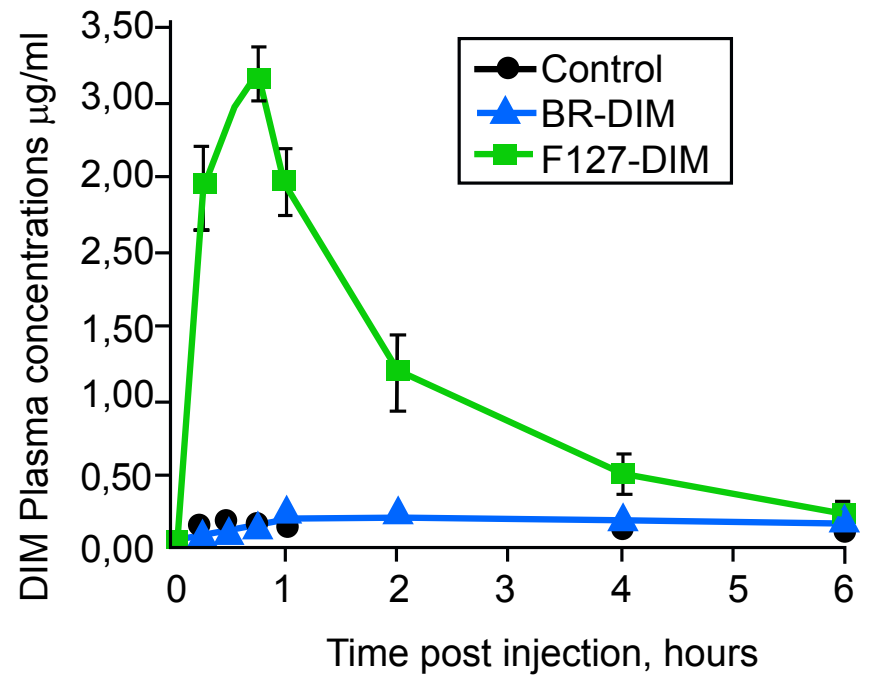

Figure 1: DIM plasma elimination for Control (non-formulated crystalline DIM) BioResponse DIM (BR-DIM) and F127-DIM formulation (F127-DIM), after oral administration to female Sprague-Dawley rats by aqueous gavage $(3 \mathrm{mg} / \mathrm{mL})$, at the dose of $60 \mathrm{mg} / \mathrm{kg}$. 
Citation: Kiselev V, Klinskiy E, Lee S, Muyzhnek E, Semov A, et al. (2013) Polymer Based Nano-Formulation of Diindolylmethane with High Oral Bioavailability. J Nanomed Nanotechol 4: 162. doi:10.4172/2157-7439.1000162

Page 3 of 3

\begin{tabular}{|c|c|c|c|c|}
\hline Formulation & $\begin{array}{l}C_{\max } \\
{[\mu g / m L]} \\
p^{*} \text { to Cntr }\end{array}$ & $\begin{array}{l}\text { Ratio } C_{\max } \\
\text { Form./Control }\end{array}$ & $\begin{array}{l}\text { AUC }_{0-6 h} \\
{[\mu g \cdot h / m L]} \\
p \text { to Cntr }\end{array}$ & $\begin{array}{l}\text { Ratio AUC } \\
\text { Form./Control }\end{array}$ \\
\hline Control & $0.18 \pm 0.02$ & - & $0.97 \pm 0.08$ & - \\
\hline BR-DIM & $\begin{array}{l}0.22 \pm 0.02 \\
p=0.207\end{array}$ & 1.22 & $\begin{array}{l}1.05 \pm 0.05 \\
p=0.429\end{array}$ & 1.08 \\
\hline F127-DIM & $\begin{array}{l}3.08 \pm 0.17 \\
p<0.0001\end{array}$ & 17.11 & $\begin{array}{l}7.06 \pm 0.93 \\
p=0.0006\end{array}$ & 7.28 \\
\hline
\end{tabular}

*- p-values calculated by two-tailed t-test

Table 1: $\mathrm{C}_{\max }$ and $A \cup \mathrm{C}_{0-6 \mathrm{~h}}$ values calculated for the animals treated with Control (non-formulated crystalline DIM), BioResponse DIM (BR-DIM), and F127-DIM formulation (F127-DIM).

results of the ongoing studies in healthy volunteers provide strong evidence of translationability of the results presented herein, in to the human patients.

\section{References}

1. Safe S, Papineni S, Chintharlapalli S (2008) Cancer chemotherapy with indole3-carbinol, bis(3'-indolyl)methane and synthetic analogs. Cancer Lett 269: 326338.
2. Weng JR, Tsai CH, Kulp SK, Chen CS (2008) Indole-3-carbinol as a chemopreventive and anti-cancer agent. Cancer Lett 262: 153-163.

3. Banerjee S, Kong D, Wang Z, Bao B, Hillman GG, et al. (2011) Attenuation of multi-targeted proliferation-linked signaling by 3,3'-diindolylmethane (DIM): from bench to clinic. Mutat Res 728: 47-66.

4. Hall JM, Barhoover MA, Kazmin D, McDonnell DP, Greenlee WF, et al. (2010) Activation of the aryl-hydrocarbon receptor inhibits invasive and metastatic features of human breast cancer cells and promotes breast cancer cell differentiation. Mol Endocrinol 24: 359-369.

5. Semov A, lourtchenco L, Liu LF, Li S, Xu Y, et al. (2012) Diindolilmethane (DIM) selectively inhibits cancer stem cells. Biochem Biophys Res Commun 424: 45-51.

6. Banerjee S, Parasramka M, Sarkar FH (2012) Cellular molecular and biological insight into chemopreventive and therapeutic potential of 3,3'-diindolylmethane (DIM). Nutraceuticals and Cancer 111-134.

7. Kiselev VI, Vasilyeva IG (2011) A pharmaceutical composition for peroral administration of diindolylmethane. WO 2011/034465 A1.

8. Raymond CR, Paul JS, Paul JW, Ray R, Paul S, et al. (2003) Hand book of pharmaceutical excipients. ( $4^{\text {th }}$ edn), Science and Practice, Royal Pharmaceutical Society of Great Britain, London, UK 447-450. 